\title{
Percentage of Gutta-Percha-, Sealer-, and Void- Filled Areas in Oval-Shaped Root Canals Obturated with Different Filling Techniques: A Confocal Laser Scanning Microscopy Study
}

Vinicio Hidemitsu Goto Hirai ${ }^{1}$ Ricardo Machado ${ }^{2}$ Maria Carolina Lucato Budziak ${ }^{1} \quad$ Lucila Piasecki $^{3}$ Alexandre Kowalczuck ${ }^{1}$ Ulisses Xavier da Silva Neto ${ }^{1}$

${ }^{1}$ Department of Endodontics, School of Health and Bioscience, Pontifical Catholic University of Paraná, Curitiba, Paraná, Brazil

${ }^{2}$ Clinical Practice Limited to Endodontics, Navegantes, Santa Catarina, Brazil

${ }^{3}$ Department of Periodontics and Endodontics, University at Buffalo, Buffalo, New York, United States

Eur J Dent 2020;14:8-12

\begin{abstract}
Address for correspondence Ricardo Machado, DDS, MSc, PhD, Clinical Practice Limited to Endodontics, Rua Brasília, 300, Apto. 503, Ed. Vila dos Ipês, Centro, Navegantes, Santa Catarina, CEP, 88.370-100, Brazil (e-mail: ricardo.machado.endo@gmail.com).
\end{abstract}

\begin{abstract}
Keywords

- oval-shaped canals

- gutta-percha-filled area

- sealer

- voids

- filling techniques

Objective This study compared different obturation techniques, analyzing percentage of areas filled with gutta-percha, sealer, and voids (PGFA, PSFA, and PVFA, respectively) in oval-shaped root canals.

Materials and Methods A total of 60 extracted human mandibular central incisors were decoronated, instrumented, and irrigated using the same protocol. After drying, the root canal was filled with AH Plus labeled with $0.1 \%$ rhodamine B dye using a Lentulo spiral. The filling procedure was performed by dividing the teeth into four groups according to the respective technique: $G 1$, cold lateral condensation; $G 2$, continuous wave of condensation; G3, modified cold lateral condensation using an F3 master cone; and G4, modified continuous wave of condensation using an ISO (International Organization for Standardization) sized 30 gutta-percha cone. Then, slices measuring $1.5 \mathrm{~mm}$ in thickness were obtained 3 and $6 \mathrm{~mm}$ from the apex and evaluated by confocal laser scanning microscopy to determine PGFA, PSFA, and PVFA.

Statistical Analysis The data were analyzed statistically with analysis of variance and Games-Howell's tests $(p=0.05)$.

Results The groups showed no significant differences in the apical third ( $3 \mathrm{~mm}$ from the apex). In the middle third (6 mm from the apex), G3 and G1 showed higher PGFA and PVFA, respectively. G3 showed lower PSFA than G2 and G4. Both cold techniques (G1 and G3) promoted lower PSFA than both warm techniques (G2 and G4).

Conclusions Notwithstanding the limitations of this in vitro study, PGFA, PSFA, and PVFA ranged significantly only in the middle third, as observed by the different filling techniques. Higher PGFA and PVFA values were obtained for $G 3$ and G1, respectively. Both cold techniques promoted lower PSFA than both warm techniques.
\end{abstract}

\section{Introduction}

Endodontic treatment aims to maintain or reestablish the health of periapical tissues by cleaning and filling the root canals. ${ }^{1,2}$ Biomechanical preparation and intracanal dressing (when used) are responsible for disinfection; however, they are not able to completely eliminate the root canal system content. $^{3,4}$ Therefore, an effective root canal filling must be performed to maintain cleanliness, trap remaining 
microorganisms, interrupt the supply of nutrients needed for their survival, and avoid contamination or recontamination. ${ }^{5}$

Obturation has most commonly been performed with gutta-percha and a sealer. Schilder ${ }^{1}$ and Epley et $\mathrm{al}^{6}$ suggested that root canal filling material should adapt adequately to the canal walls as well as its irregularities. Furthermore, it is important that gutta-percha be placed along the entire length of the canal, be densely compacted, and consist of a homogeneous mass. For this reason, a widely used strategy to evaluate the quality of obturations is to analyze the percentages of areas filled with gutta-percha, sealer and voids (PGFA, PSFA, and PVFA, respectively). ${ }^{7.8}$

The cold lateral condensation technique (CLCT) is the most common approach used in endodontic clinics. Its advantages include relative ease of use, low cost, predictability, and controlled placement. However, this technique has been known to leave voids, use an excessive amount of sealer, and be deficient in adapting gutta-percha adequately to root canal walls. ${ }^{5}$

The warm vertical condensation technique enables gutta-percha to be provided in a homogeneous and dimensionally stable mass; this makes it easier for the material to penetrate root canal system ramifications. This technique has been simplified by certain recently introduced devices such as System B (SybronEndo; Orange, California, United States). This or similar equipment allows the heating of the filling material in a single step. Moreover, this approach leads to the creation of the continuous wave of condensation technique (CWCT). CWCT is not only a more costly technique, requiring specific equipment, but it also promotes higher extrusion of filling materials. ${ }^{5}$

No obturation technique can completely fill the root canal. ${ }^{5}$ This limitation is even more critical in teeth with oval canals, such as the mandibular incisors. ${ }^{9,10}$ For this reason, different materials, ${ }^{11,12}$ techniques, ${ }^{13,14}$ and modifications ${ }^{15,16}$ have been proposed and studied using several methodologies. ${ }^{17,18}$

One of the preferred tools to assess the adhesive interface and the topographic features of the root canal filling is confocal laser scanning microscopy (CLSM). It stands out because it allows samples to be measured in depth despite a wet environment. A fluorescent dye is used to mark root canal sealers so that they can be analyzed under CLSM. Certain dyes are added to sealers to cause certain wavelengths to excite the marked structure for the purpose of making the spectrum visible. CLSM is capable of accurately determining the degree of adaptation and penetration of the root canal filling materials. ${ }^{18}$

This in vitro study aimed at determining PGFA, PSFA, and PVFA in oval-shaped root canals obturated with CLCT and CWCT and assessing two respective procedural modifications using CLSM.

\section{Materials and Methods}

\section{Tooth Selection}

Sixty extracted human mandibular central incisors were selected for this study after approval by the University Research Ethics Committee (no. 5690/11). The selection was based on acquiring teeth with straight and single root canals ending in just one main apical foramen, without radicular cracks, resorption process, or other anatomical complexities, and with prior endodontic treatment. Buccal and proximal radiographs, and a stereomicroscope under 20× magnification (Expert DN; Mueller-Optronic, Erfurt, Germany) were used to confirm these features. The teeth were kept in a $0.1 \%$ thymol solution at $4^{\circ} \mathrm{C}$ until use.

\section{Root Canal Shaping and Filling}

The roots of the teeth were standardized at $14 \mathrm{~mm}$ in length by sectioning tooth crowns with a low-speed steel cutting disc (IsoMet, Buehler, Lake Bluff, Illinois, United States). Root canal orifices were prepared with a 3082 tapered-tip bur (KG Sorensen, São Paulo, Brazil) and a Largo No. 2 drill (Dentsply-Maillefer, Ballaigues, Switzerland), whereas cervical and middle thirds were prepared using Gates-Glidden No. 3 and No. 2 drills (Dentsply-Maillefer). The working lengths (WLs) were established at $1 \mathrm{~mm}$ short of the point where a 15-K file (Dentsply-Maillefer) was visible at the apical foramen.

Instrumentation of root canals used the crown-down technique and rotary ProTaper instruments (Dentsply-Maillefer) up to size F3 at the WL. At each change of file, the canals were irrigated with $2.5 \mathrm{~mL}$ of $2.5 \% \mathrm{NaOCl}$ (Fórmula \& Ação, São Paulo, Brazil) prepared immediately before, together with a flush of $3 \mathrm{~mL}$ of $17 \%$ ethylenediaminetetraacetic acid (EDTA) (Fórmula \& Ação) for 3 minutes. The final rinse consisted of $5 \mathrm{~mL}$ of sterile water. The root canals were dried with sterile absorbent paper points (Tanari, São Paulo, Brazil). A 10- $\mu \mathrm{L}$ aliquot of AH Plus (Dentsply DeTrey, Konstanz, Germany), labeled with $0.1 \%$ Rhodamine B dye (Sigma-Aldrich, St. Louis, Missouri, United States), was placed into the root canal using a size 20 Lentulo spiral in a counterclockwise rotation.

The filling procedure was performed by dividing the teeth into four groups $(n=15)$ according to the respective technique ( - Table 1). The teeth were then stored in $100 \%$ humidity at $37^{\circ} \mathrm{C}$ for 2 weeks.

\section{Confocal Laser Scanning Microscopy}

The filled specimens were embedded in crystal resin to obtain 1.5-mm-thick cross-sections 3 and $6 \mathrm{~mm}$ from the apex using a diamond cutting disc $(\varnothing 127 \mathrm{vmm} \times 0.4 \mathrm{vmm} \times 12.7 \mathrm{vmm}$, Buehler, Ltd. Lake Bluff, IL, United States) coupled to an automatic precision cutter (IsoMet 4000, Buehler Ltd.) at a speed of $5 \mathrm{~mm} /$ minute at $400 \mathrm{rpm}$ rotational speed and under abundant water cooling, resulting in a total of 120 slices. The coronally facing surface of each slice was polished with a standard procedure to produce a surface of high reflection.

Images were then taken by CLSM (Leica, Jena, Germany) for analysis of the PGFA, PSFA, and PVFA using two Ne-He laser beams excited with a 568-nm wavelength. The teeth were scanned axially and laterally using the fluorescence mode with a resolution of 220 and $330 \mathrm{~nm}$, respectively. Root third images were obtained by Leica Microsystems LAS AF TCS MP5 software (Leica, Jena, Germany). The images were

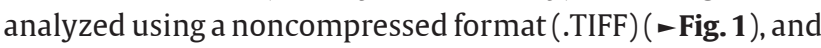
the measurements were performed using Adobe Photoshop Cs3 (Adobe, San Jose, California, United States) by a single operator. Each section was measured three times, and the means were calculated. Areas of gutta-percha, sealer, and 
void were converted into percentages (PGFA, PSFA, and PVFA, respectively) of the total canal area.

\section{Statistical Analysis}

The data were analyzed statistically using analysis of variance and Games-Howell's tests, with a significance level set at $p=0.05$.

\section{Results}

No significant differences in PGFA, PSFA, and PVFA were observed in the apical thirds among the groups $(p>0.05)$. The higher PGFA and PVFA values were obtained in G3 and G1, respectively $(p<0.05)$. Both G1 and G3 promoted lower PSFA than G2 and G4 ( $p<0.05)$ (-Table 2).

\section{Discussion}

Obturation of a shaped and cleaned root canal is most effective when a maximum amount of gutta-percha is packed into the canal, and sealer amounts are kept to a minimum because most sealers shrink on setting and dissolve over time, unlike gutta-percha, which is dimensionally stable. ${ }^{5}$ For this reason, PGFA, PSFA, and PVFA were used in the investigation to assess obturation quality based on the procedure used in previous studies. ${ }^{7,8}$

The main disadvantages of CLCT and CWCT are the excessive quantity of sealer and voids and the extrusion of filling materials, respectively. ${ }^{5}$ For these reasons, we proposed two respective procedural modifications to offset these adverse features, namely, the use of matched tapered master cones for performing CLCT (G3-MCLCT) and standardized cones for performing CWCT (G4-MCWCT).

In regard to PGFA, PSFA, and PVFA, no significant differences in the apical third ( $3 \mathrm{~mm}$ from the apex) were observed among the groups ( $p>0.05)$, corroborating the results found in previous studies. ${ }^{8,19,20}$ Leoni et al ${ }^{21}$ used microcomputed tomography (CT) to study the anatomy of 100 mandibular central and lateral incisors. At $3 \mathrm{~mm}$ from the apex, mandibular central and lateral incisors showed areas of $0.16 \pm 0.12$ and $0.14 \pm 0.08 \mathrm{~mm}^{2}$ and roundness of $0.43 \pm 0.22$ and $0.46 \pm 0.21$, respectively. This study performed instrumentation up to the

Table 1 Groups and protocols for root canal fillings

\begin{tabular}{|l|l|}
\hline Group & Protocol \\
\hline G1 (CLCT) & $\begin{array}{l}\text { Cold lateral condensation technique was performed with an ISO-sized } 30 \text { gutta-percha master cone (Tanari). A size } \\
25 \text { NiTi finger spreader calibrated up to } 1 \mathrm{~mm} \text { from the WL was introduced up to the allowed depth. R7 accessory } \\
\text { cones (Tanari) were used for lateral condensation. As many accessory cones as possible were placed in the canal. }\end{array}$ \\
\hline G2 (CWCT) & $\begin{array}{l}\text { Continuous wave of condensation technique was performed using an F3 master cone (Dentsply-Maillefer) with a } \\
\text { sectioned tip locked at } 1 \mathrm{~mm} \text { short of the WL. The heat carrier of System B (SybronEndo) was used up to } 5 \text { mm } \\
\text { from the WL. }\end{array}$ \\
\hline G3 (MCLCT) & The same protocol described for G1 but using an F3 master cone. \\
\hline G4 (MCWCT) & The same protocol described for G2 but using an ISO-sized 30 gutta-percha cone. \\
\hline
\end{tabular}

Abbreviations: CLCT, cold lateral condensation technique; CWCT, continuous wave of condensation technique; ISO, International Organization for Standardization; MCLCT, modified cold lateral condensation technique; MCWCT, modified continuous wave of condensation technique; WL, working length.

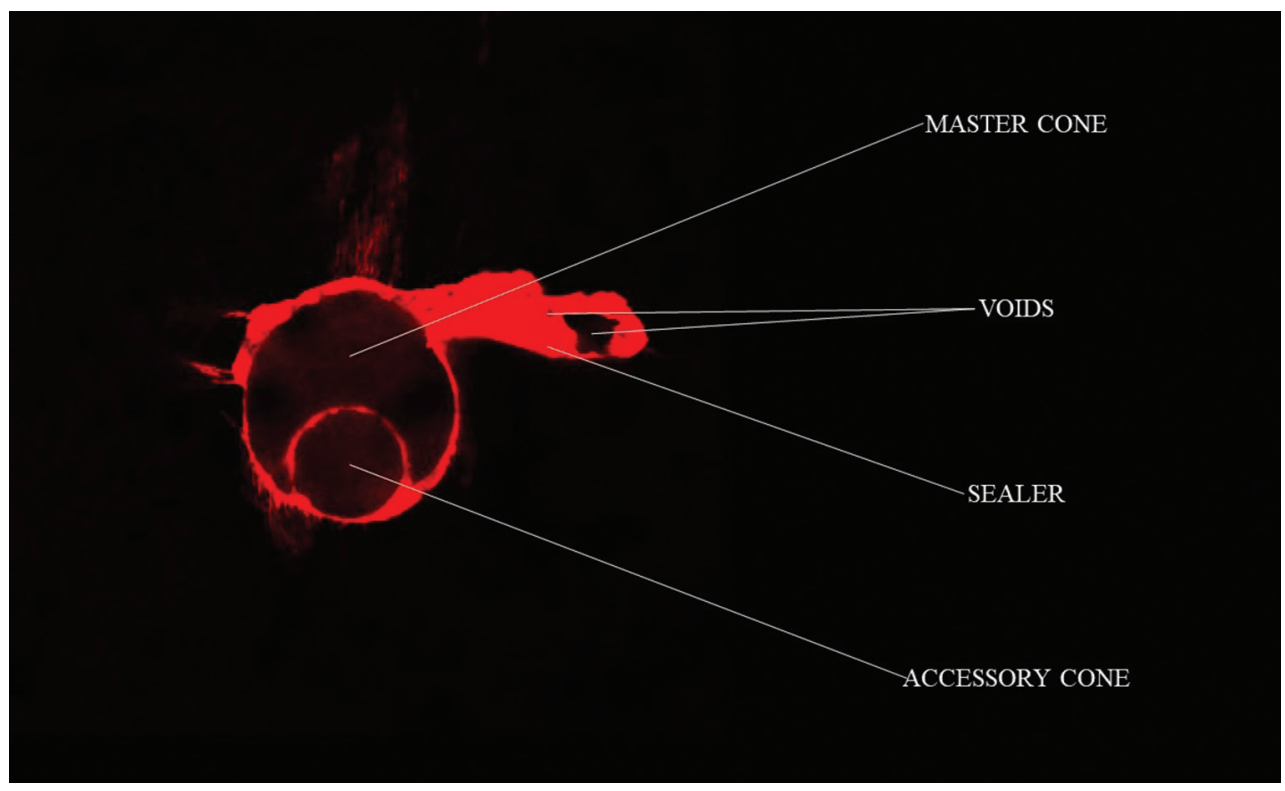

Fig. 1 Illustrative confocal laser scanning microscopy image used for analysis. 
Table 2 PGFA, PSFA, and PVFA in each third

\begin{tabular}{|l|l|l|l|l|l|l|}
\hline \multirow{2}{*}{ Group $(\boldsymbol{n}=15)$} & \multicolumn{2}{|l|}{ Apical third } & \multicolumn{2}{l|}{ Middle third } \\
\cline { 2 - 7 } & $\begin{array}{l}\text { PGFA, } \\
\text { mean } \pm \text { SD }\end{array}$ & $\begin{array}{l}\text { PSFA, } \\
\text { mean } \pm \text { SD }\end{array}$ & $\begin{array}{l}\text { PVFA, } \\
\text { mean } \pm \text { SD }\end{array}$ & $\begin{array}{l}\text { PGFA, } \\
\text { mean } \pm \text { SD }\end{array}$ & $\begin{array}{l}\text { PGSA, } \\
\text { mean } \pm \text { SD }\end{array}$ & $\begin{array}{l}\text { PVFA, } \\
\text { mean } \pm \text { SD }\end{array}$ \\
\hline$G 1$ & $67.30 \pm 11.76^{\mathrm{a}}$ & $29.84 \pm 11.33^{\mathrm{a}}$ & $1.62 \pm 1.47^{\mathrm{a}}$ & $62.85 \pm 10.44^{\mathrm{b}}$ & $28.81 \pm 7.18^{\mathrm{b}, \mathrm{c}}$ & $4.53 \pm 2.19^{\mathrm{b}}$ \\
\hline G2 & $62.77 \pm 6.54^{\mathrm{a}}$ & $36.59 \pm 6.71^{\mathrm{a}}$ & $0.40 \pm 0.28^{\mathrm{a}}$ & $61.93 \pm 11.76^{\mathrm{b}}$ & $36.50 \pm 10.86^{\mathrm{b}}$ & $1.22 \pm 1.22^{\mathrm{c}}$ \\
\hline G3 & $65.79 \pm 12.20^{\mathrm{a}}$ & $32.50 \pm 11.89^{\mathrm{a}}$ & $1.05 \pm 0.86^{\mathrm{a}}$ & $77.15 \pm 11.05^{\mathrm{c}}$ & $19.39 \pm 10.45^{\mathrm{c}}$ & $2.00 \pm 1.78^{\mathrm{c}}$ \\
\hline G4 & $56.60 \pm 8.91^{\mathrm{a}}$ & $42.22 \pm 11.22^{\mathrm{a}}$ & $0.76 \pm 0.68^{\mathrm{a}}$ & $54.10 \pm 16.82^{\mathrm{b}}$ & $43.88 \pm 16.30^{\mathrm{b}}$ & $1.59 \pm 1.58^{\mathrm{c}}$ \\
\hline
\end{tabular}

Abbreviations: PGFA, percentage of areas filled with gutta-percha; PSFA, percentage of areas filled with sealer; PVFA, percentage of areas filled with voids.

Note: Different superscript letters indicate statistically significant differences $(p<0.05)$.

F3 file at the WL established at $1 \mathrm{~mm}$ short of the apical foramen. The canals were then instrumented up to approximately $0.48 \mathrm{~mm}^{2}$ at $3 \mathrm{~mm}$ from this region. This shaping process was responsible for regularizing the canals in terms of circularity, mainly in the apical third, thus increasing obturation quality, regardless of the technique. ${ }^{22,23}$

In the middle third (6 $\mathrm{mm}$ from the apex), G1 presented higher PVFA than the other groups $(p<0.05)$. Several studies have shown limitations of the CLCT for filling ovalshaped canals in the cervical and middle thirds. ${ }^{10,24}$ Schäfer et $\mathrm{al}^{25}$ evaluated PGFA, PSFA, and PVFA after shaping and filling 60 extracted mandibular incisors with the following systems: (A) FlexMaster (VDW Antaeos; Munich, Germany), (B) Mtwo (VDW; Munich, Germany), (C) ProTaper (Dentsply; Weybridge, Surrey, United Kingdom), (D) Reciproc (VDW; Munich, Germany), (E) WaveOne (Dentsply Maillefer; Ballaigues, Switzerland), and (F) manual instrumentation. In groups $\mathrm{A}-\mathrm{E}$ and $\mathrm{F}$, they used matching single-cone gutta-percha and CLCT, respectively, to perform the fillings. Curiously, group F produced similar PVFA results at the $6-\mathrm{mm}$ level compared with group C. These results contrast with our findings, in which G1 presented higher PVFA than the other groups. However, it is noteworthy to mention an important point about the methodology used in the study performed by Schäfer et a ${ }^{25}$ : there were four cases of teeth with an oval canal or a canal with isthmuses when the teeth were sectioned; in this case, they were replaced by a new one. The authors did not report from which groups these teeth were removed and replaced. This is an important bias of the study, which even may have influenced the results, considering that the performance of CLCT may be improved in teeth with circular canals. ${ }^{22,23}$

Still, in regard to the middle third, higher PGFA values were obtained in G3 compared with the other groups $(p<0.05)$. The accessory cone sizes and tapers chosen were smaller than the finger spreader so that GP could be placed in the entire extension of the space created. ${ }^{26}$ However, in G3 specimens, finger spreader penetration was limited to the initial millimeters of the root canal because an F3 cone was used. In G1 specimens, the finger spreader reached the final millimeters of the root canal, mainly at the beginning of lateral condensation. The G1 specimens commonly showed large unfilled round-shaped voids (spreader tracks). ${ }^{24}$ The reason the spreader tracks remained unfilled could be that there was a size variation in the accessory cones of the same brand $^{27}$ and that there was no standardization between spreader size and accessory cones..$^{28}$ The arguments mentioned above explain the higher PGFA and PVFA of both G3 and G1 compared with the other groups.

All thermoplasticized gutta-percha techniques have a common feature, which is the heating of gutta-percha to an extremely high temperature such as $200^{\circ} \mathrm{C}$ to $400^{\circ} \mathrm{C}$ to ensure that the gutta-percha mass melts homogeneously. ${ }^{29}$ However, high-temperature settings risk degradation of gutta-percha and the formation of new compounds of low molecular mass such as peroxides and volatile products. ${ }^{30}$ The loss of material stability and reduction in molar mass may explain both the higher PGFA of G3, compared with the other groups, and the lower PSFA of G3, compared with G2 and G4. According to Capurro et al, ${ }^{31} 2$ minutes after obturation using the warm vertical condensation technique, the gutta-percha underwent significant shrinkage. Moreover, there were large areas of no adaptation that increased even more after 5 minutes and 30 minutes.

This study used CLSM because it has advantages that are unavailable with scanning electron microscopy and histological methods. These include providing detailed information on gutta-percha, sealer, and void distribution in the total circumference of the root canal at a magnification as low as $50 \times$ to $100 \times$ using just one image. ${ }^{32,33}$ Furthermore, CLSM allows different analyses to be made under environmental conditions, with no special specimen processing, resulting in lower production of technique artifacts. ${ }^{34}$ The drawback is that CLSM does not give volume information, unlike micro-CT data, and uses a technique that can be considered as destructive. Therefore, it is important that future studies be conducted using micro-CT to elucidate the impact of each filling technique on the complex root canal anatomy. ${ }^{19}$

\section{Conclusion}

Notwithstanding the limitations of this in vitro study, PGFA, PSFA, and PVFA ranged significantly only in the middle third ( $6 \mathrm{~mm}$ from the apex), as observed by the different filling techniques. Higher PGFA and PVFA values were obtained for G3 and G1, respectively. Both cold techniques (G1 and G3) promoted lower PSFA than both warm techniques (G2 and G4). 


\section{Conflict of Interest}

None declared.

\section{References}

1 Schilder H. Filling root canals in three dimensions. Dent Clin North Am 1967:723-744

2 Schilder H. Cleaning and shaping the root canal. Dent Clin North Am 1974;18(2):269-296

3 Üreyen Kaya B, Erik CE, Sesli Çetin E, Köle M, Maden M. Mechanical reduction in intracanal Enterococcus faecalis when using three different single-file systems: an ex vivo comparative study. Int Endod J 2019;52(1):77-85

4 Martinho FC, Gomes CC, Nascimento GG, Gomes APM, Leite FRM. Clinical comparison of the effectiveness of 7- and 14-day intracanal medications in root canal disinfection and inflammatory cytokines. Clin Oral Investig 2018;22(1):523-530

5 Whitworth J. Methods of filling root canals: principles and practices. Endod Topics 2005;12(5):2-24

6 Epley SR, Fleischman J, Hartwell G, Cicalese C. Completeness of root canal obturations: epiphany techniques versus guttapercha techniques. J Endod 2006;32(6):541-544

7 Libonati A, Montemurro E, Nardi R, Campanella V. Percentage of gutta-percha-filled areas in canals obturated by 3 different techniques with and without the use of endodontic sealer. J Endod 2018;44(3):506-509

8 Schäfer E, Schrenker C, Zupanc J, Bürklein S. Percentage of gutta-percha filled areas in canals obturated with cross-linked gutta-percha core-carrier systems, single-cone and lateral compaction technique. J Endod 2016;42(2):294-298

9 De-Deus G, Barino B, Marins J, Magalhães K, Thuanne E, Kfir A. Self-adjusting file cleaning-shaping-irrigation system optimizes the filling of oval-shaped canals with thermoplasticized gutta-percha. J Endod 2012;38(6):846-849

10 Nhata J, Machado R, Vansan LP, et al. Micro-computed tomography and bond strength analysis of different root canal filling techniques. Indian J Dent Res 2014;25(6):698-701

11 Strange KA, Tawil PZ, Phillips C, Walia HD, Fouad AF. Longterm outcomes of endodontic treatment performed with resilon/epiphany. J Endod 2019;45(5):507-512

12 Piai GG, Duarte MAH, Nascimento ALD, Rosa RAD, Só MVR, Vivan RR. Penetrability of a new endodontic sealer: a confocal laser scanning microscopy evaluation. Microsc Res Tech 2018;81(11):1246-1249

$13 \mathrm{Xu} \mathrm{H}$, Qiu XH, Zhang GD, Zhang FM. Evaluation of the filling quality of different root canal obturation techniques using micro-CT [in Chinese]. Shanghai Kou Qiang Yi Xue 2018;27(4):349-353

14 Fragachán M, Pons M, Barriuso E, Frigola J, Ballester ML, Berástegui E. Micro-computed tomography assessment of different obturation techniques for filling lateral canals. J Clin Exp Dent 2018;10(7):e702-e708

15 Dumani A, Yilmaz S, Yoldas O, Kuden C. Evaluation of various filling techniques in distal canals of mandibular molars instrumented with different single-file nickel-titanium systems. Niger J Clin Pract 2017;20(3):307-312

16 Soo WK, Thong YL, Gutmann JL. A comparison of four gutta-percha filling techniques in simulated C-shaped canals. Int Endod J 2015;48(8):736-746

17 Huang Y, Orhan K, Celikten B, Orhan AI, Tufenkci P, Sevimay S. Evaluation of the sealing ability of different root canal sealers: a combined SEM and micro-CT study. J Appl Oral Sci 2018;26:e20160584

18 Tedesco M, Chain MC, Bortoluzzi EA, da Fonseca Roberti Garcia L, Alves AMH, Teixeira CS. Comparison of two observational methods, scanning electron and confocal laser scanning microscopies, in the adhesive interface analysis of endodontic sealers to root dentine. Clin Oral Investig 2018;22(6):2353-2361

19 Marciano MA, Ordinola-Zapata R, Cunha TV, et al. Analysis of four gutta-percha techniques used to fill mesial root canals of mandibular molars. Int Endod J 2011;44(4):321-329

20 De-Deus G, Gurgel-Filho ED, Magalhães KM, Coutinho-Filho T. A laboratory analysis of gutta-percha-filled area obtained using Thermafil, System B and lateral condensation. Int Endod J 2006;39(5):378-383

21 Leoni GB, Versiani MA, Pécora JD, Damião de Sousa-Neto M. Micro-computed tomographic analysis of the root canal morphology of mandibular incisors. J Endod 2014;40(5):710-716

22 van der Sluis LW, Wu MK, Wesselink PR. An evaluation of the quality of root fillings in mandibular incisors and maxillary and mandibular canines using different methodologies. J Dent 2005;33(8):683-688

23 Keçeci AD, Unal GC, Sen BH. Comparison of cold lateral compaction and continuous wave of obturation techniques following manual or rotary instrumentation. Int Endod J 2005;38(6):381-388

24 Souza EM, Wu MK, van der Sluis LW, Leonardo RT, Bonetti-Filho I, Wesselink PR. Effect of filling technique and root canal area on the percentage of gutta-percha in laterally compacted root fillings. Int Endod J 2009;42(8):719-726

25 Schäfer E, Köster M, Bürklein S. Percentage of gutta-percha-filled areas in canals instrumented with nickel-titanium systems and obturated with matching single cones. J Endod 2013;39(7):924-928

26 Gound TG, Riehm RJ, Odgaard EC, Makkawy H. Effect of spreader and accessory cone size on density of obturation using conventional or mechanical lateral condensation. J Endod 2001;27(5):358-361

27 Moule AJ, Kellaway R, Clarkson R, et al. Variability of master gutta-percha cones. Aust Endod J 2002;28(1):38-43

28 Hartwell GR, Barbieri SJ, Gerard SE, Gunsolley JC. Evaluation of size variation between endodontic finger spreaders and accessory gutta-percha cones. J Endod 1991;17(1):8-11

29 Cheng YA, Huang SH, Hsien HC, Chiang YC, Lin CP. Influence of cyclic heating on physical property and biocompatibility of $\alpha$ - and $\beta$-form gutta-percha. J Formos Med Assoc 2014;113(8):498-505

30 Maniglia-Ferreira C, Bönecker G, Silva JB Jr, de Paula RC, Feitosa JP, Souza-Filho FJ. Degradation of trans-polyisoprene after root filling with thermoplasticized techniques. Int Endod J 2008;41(4):296-302

31 Capurro MA, Goldberg F, Balbachan L, Macchi RL. Evaluation of the dimensional stability of different thermoplasticized gutta-percha fillings using simulated glass root canals. Endod Dent Traumatol 1993;9(4):160-164

32 Ordinola-Zapata R, Bramante CM, Graeff MS, et al. Depth and percentage of penetration of endodontic sealers into dentinal tubules after root canal obturation using a lateral compaction technique: a confocal laser scanning microscopy study. Oral Surg Oral Med Oral Pathol Oral Radiol Endod 2009;108(3):450-457

33 D'Alpino PH, Pereira JC, Svizero NR, Rueggeberg FA, Pashley DH. Use of fluorescent compounds in assessing bonded resin-based restorations: a literature review. J Dent 2006;34(9):623-634

34 Bitter K, Paris S, Martus P, Schartner R, Kielbassa AM. A confocal laser scanning microscope investigation of different dental adhesives bonded to root canal dentine. Int Endod 2004;37(12):840-848 